\title{
Academics and Athletics: Do Position and Field of Play Matter? A Response to "Academics and Athletics: A Part and Apart in the American Campus"
}

\author{
Janet H. Lawrence \\ University of Michigan
}

Thank you for inviting me to respond to Professor Thelin's observations about athletics and academics in America's universities. Unlike Professor Thelin, with his impressive record of scholarship on college sports, I'm a newcomer to this important area of inquiry pulled in as a result of the national survey of faculty that I conducted for the Knight Commission on Intercollegiate Athletics. Consequently, I decided the most meaningful contribution I can make to the present discussion is to share select study findings that relate to Professor Thelin's argument, shedding light on how faculty comprehend the fit of college sports within higher education and suggesting directions for research into how they construct different interpretations.

Drawing on his extensive knowledge about the history of higher education and college sports, Professor Thelin argues persuasively that intercollegiate athletics has become one of higher education's peculiar institutions-like university hospitals and musical societies - that serve students and the public and whose membership in the campus community is regulated by a unique set of agreements and understandings. Throughout history, athletic departments have been "a part and apart in the American campus."

I'm a social scientist interested in individual and group beliefs and behaviors, how situations are perceived, and the processes through which this knowledge influences people's decisions and actions. The title of my response, "Academics and Athletics: Do Position and Field of Play Matter," reflects my assumption that individuals' experiences with intercollegiate athletics on their particular campus shape their beliefs about the interrelatedness of athletics and academics and their interpretations of policies and practices. The question remains: In what ways do these perceptions of U.S. campuses align with the key premises that undergird Professor Thelin's position?

Some partial answers emerge in the findings of the recent national survey of faculty that I mentioned earlier. Given their traditional responsibility for upholding academic integrity on campus and recent calls for greater faculty involvement in the oversight of intercollegiate athletics, I believe a focus on faculty is appropriate to the current discussion. In my response, I will briefly introduce the study and then

The author is with the School of Education, University of Michigan, Ann Arbor, MI. 
juxtapose relevant findings with Professor Thelin's propositions, demonstrating that although faculty might agree that athletics and academics are discrete parts of the academy, perceptions of the degree and nature of the separation vary.

\section{Knight Commission Survey: Faculty Perceptions of Intercollegiate Athletics}

The primary goals of the Faculty Survey were to: (1) learn from faculty how they perceive and how satisfied they are with the academic, governance, and financial aspects of intercollegiate athletics on their campus; and (2) assess faculty willingness to engage in university-based activities designed to ameliorate their concerns about college sports. A purposive sample of faculty who were most likely to have knowledge about athletics and were more likely to interact with studentathletes in the classroom was drawn from 23 institutions in the NCAA's Football Bowl Subdivision. Two institutions were randomly selected from each of the 11 Football Bowl Subdivision conferences and one from the institutions unaffiliated with any conference.

The final sample used in the analyses included 2,071 faculty after adjusting for those who did not fully complete the survey, faculty currently on sabbatical, emeritus faculty, nontenure track faculty, and administrators inadvertently included. Within this purposive sample, $50 \%$ are involved in faculty governance beyond the department level and 14\% have experience with athletics governance; $77 \%$ currently or have in the past taught student-athletes. ${ }^{1}$

\section{Thelin's Argument}

Professor Thelin foreshadows his conclusion early in the paper. He states,

Both academics and athletics are part of the American campus. Yet they are often apart from one another, with each operating in distinctive orbits and by different codes. . . . My main resolution is that the Department of Intercollegiate Athletics stands out as higher education's "Peculiar Institution." Yes, it is part of the campus. However, its conduct and facilities suggest that it enjoys the benefits of a special zoning ordinance within the campus. As the Peculiar Institution it asks for and receives entitlements and privileges seldom received by other units. (Thelin, 2008, p. xx)

Thelin's argument builds on four key propositions:

(1) Athletics departments have special privileges not granted to academic departments,

(2) Ritualized gestures of cooperation with the academic "orbit" are used to protect the athletics departments' special arrangement,

(3) Athletics departments enjoy tacit affirmation for their "good arrangements" from central administrators, boards of trustees, and athletic associations, and

(4) Ingenious and often disingenuous structures and procedures that enable athletics departments to simultaneously be a part of and apart from the rest 
of campus become boring or wear faculty down - they become indifferent to, "disconnected from"- the practices and policies of college sports.

Given this state of affairs, Professor Thelin concludes that faculty, traditionally designated as responsibile for shared governance, are worn down. They believe they lack agency and therefore do not aggressively question or actually fight to change aspects of intercollegiate athletics that they believe lack integrity. Special arrangements are perpetuated and athletic departments remain a part and apart in American colleges.

\section{The Kaleidoscope of Faculty Perspectives}

Are faculty views of intercollegiate athletics uniform and are they collectively disengaged from the oversight of intercollegiate athletics on their campuses as Thelin surmises, or is there sufficient heterogeneity in their views to preclude broad characterizations? Turning now to the results of the Faculty Survey, I consider the extent to which faculty beliefs align with Dr. Thelin's propositions and the implications for future inquiries into the processes through which faculty construct particular interpretations of college sports and their fit within higher education.

\section{Special Privilege}

Dr. Thelin uses historic accounts of intercollegiate athletics to argue that separate athletic and academic "zones" have evolved over time and that athletic departments are accorded special privileges not extended to academic departments, such as being allowed to follow the letter rather than the spirit of rules established to regulate their activities. From a range of possible proxies for separation and special privileges, I offer three for discussion: the auxiliary status of intercollegiate athletics, faculty involvement in oversight, and athletics department integrity.

Respondents to the Faculty Survey were asked to indicate the extent to which various statements characterize intercollegiate athletics on their own campus. Figure 1 summarizes data for the total sample for the following: "Organizationally, intercollegiate athletics is an auxiliary service (e.g., campus bookstore) that generates its own revenue and is accountable to university administrators, not faculty." Figure 2 juxtaposes the responses of the total sample to two items. The first asked faculty their perceptions of how typical it is on their campus for institution-level decisions about academic matters to be made by administrators in consultation with faculty governance groups. The second asked how typical it is for decisions about intercollegiate athletics to be made by administrators after consulting with faculty. These results indicate that the majority of the total sample agrees with the premise that the operations of athletics departments are structurally separated from academic departments - they reside in a different "orbit". Furthermore, they believe that administrator-faculty consultative practices (shared governance) applied in academic areas are less prevalent in intercollegiate athletics.

This consensus erodes, however, when characteristics of respondents' employing institutions are taken into account. Figure 3 plots faculty perceptions of the auxiliary status of intercollegiate athletics by their campus' athletics revenue for the year 2004-2005. As revenues, and most likely program size, increase, faculty are 
Organizationally, intercollegiate athletics is an auxiliary service (e.g., campus bookstore) that generates its own revenue and is accountable to university administrators, not faculty

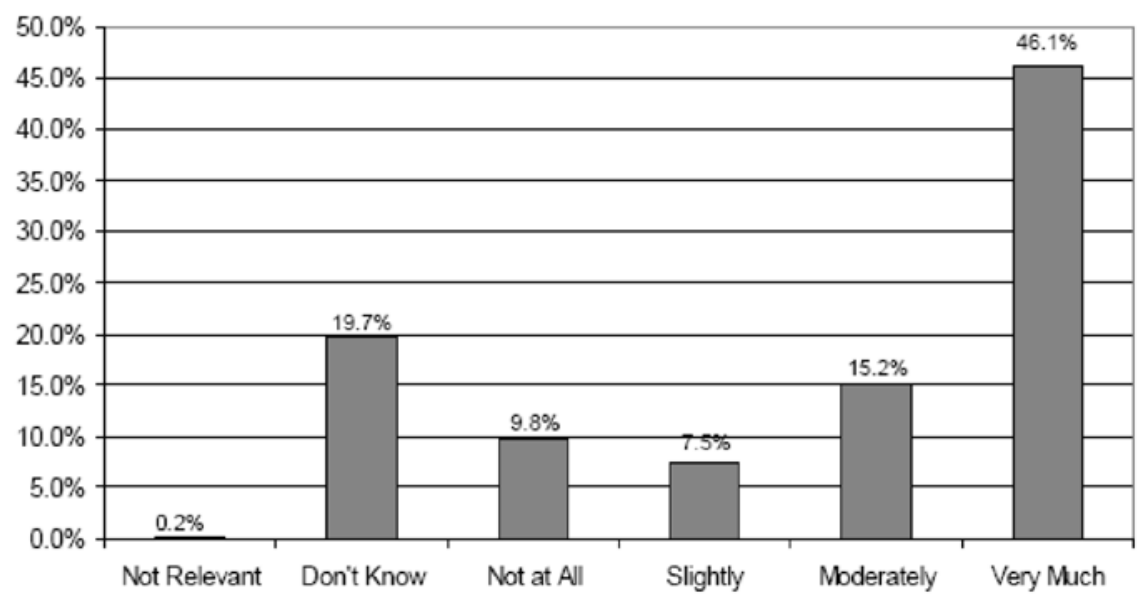

Figure 1 - Faculty perceptions of athletics as auxiliary service.

Institution-level decisions about this area are typically made by administrators who consult with faculty governance groups

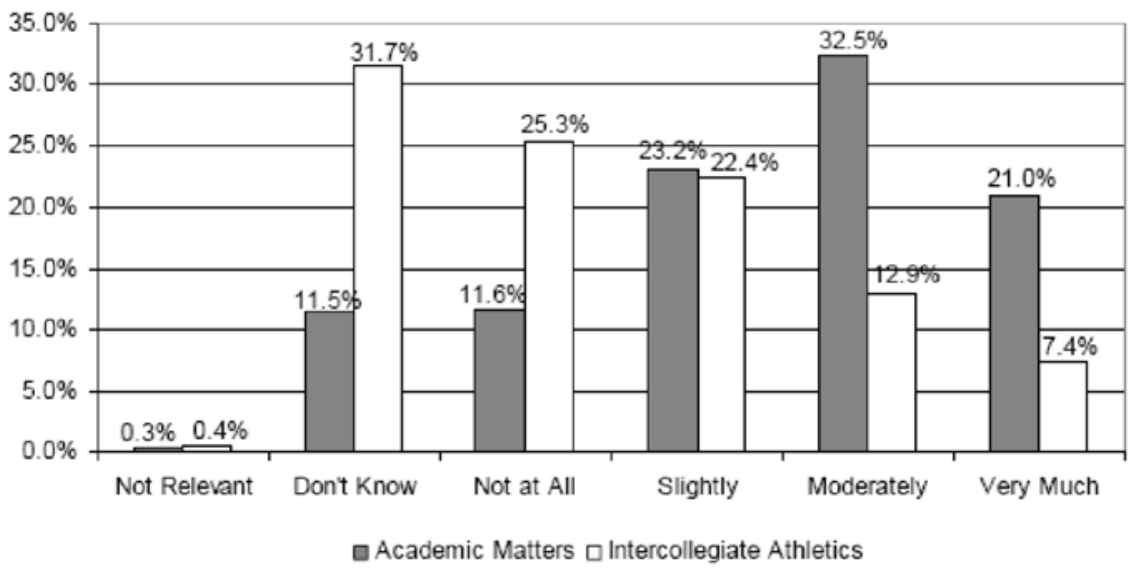

Figure 2 - Faculty perceptions of campus decision making. 


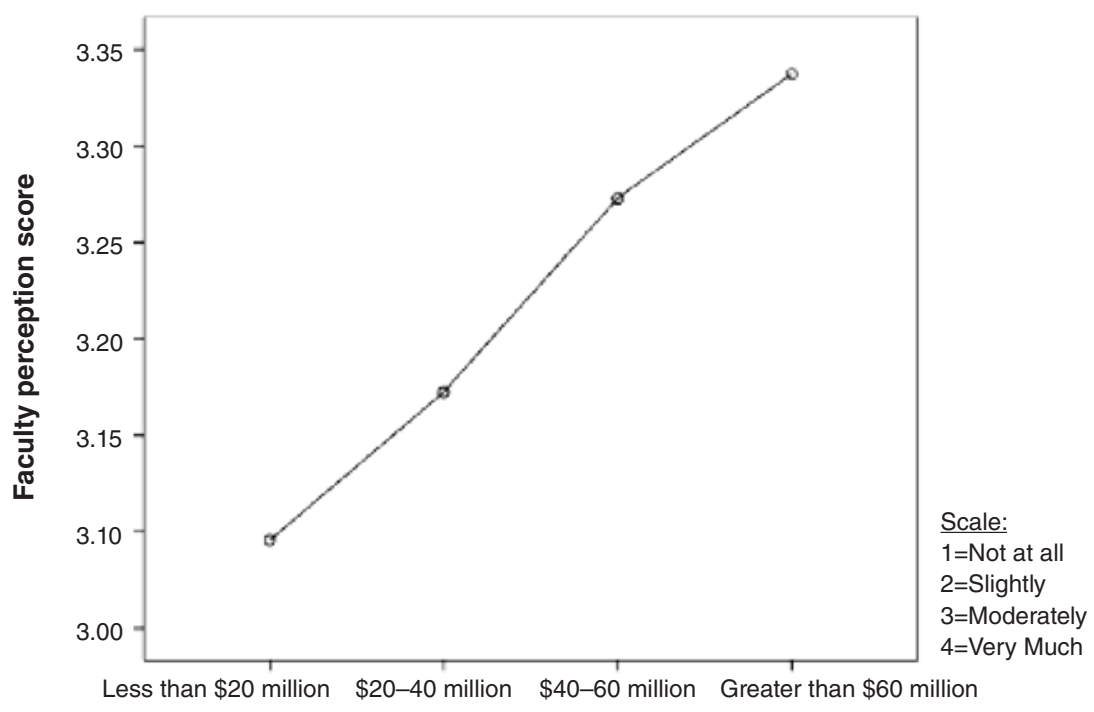

Athletics revenues

Figure 3 - Faculty perceptions of athletics as auxiliary service by athletics revenues. Response to the statement: "Organizationally, intercollegiate athletics is an auxilliary service (e.g., campus bookstore) that generates its own revenue and is accountable to university administrators, not faculty."

more likely to believe intercollegiate athletics is an auxiliary enterprise. ${ }^{2}$ Responses to other items indicate faculty who believe their campuses subsidize intercollegiate athletics with general funds are less likely to characterize their athletics departments as auxiliary enterprises.

Faculty perceptions of athletics oversight also differ by campus context. Those who are less sure faculty are consulted about academic matters tend to perceive that their athletics department gets what it wants on campus and to believe also that the athletics department is an auxiliary enterprise with policies and practices that lack transparency. However, respondents who perceive their campus climate supports faculty involvement in institutional governance generally are more likely to believe faculty are consulted on decisions related to intercollegiate athletics specifically.

During the design phase of the Faculty Survey, interviews were conducted with more than 60 faculty members who differed in intercollegiate athletics experience and held appointments in universities that varied in mission, control, and geographic location. Faculty were presented with potentially problematic scenarios involving intercollegiate athletics and academic integrity, and they were asked what actions they would propose and why. One depicted a coach explaining to the media how he "games" the NCAA Academic Progress Report. Many respondents reacted quite cynically, drawing parallels between the given situation and the ways their universities approach other exercises such as campus rankings. Interviewers were 
left with a strong impression that faculty believe adherence to the letter and not the spirit of the law-technical correctness - typifies contemporary practices in both athletic and academic domains.

When respondents to the Faculty Survey characterized their athletic departments in terms of adherence to NCAA and institutional regulations, the majority of the total sample (56\%) said it is moderately to very much the case that over the past 5 years, their athletics departments ran "clean" programs (e.g., no abuses, no major violations). However, the presurvey interviews suggested, and survey results confirm, that faculty views vary based on perceptions of the community that surrounds their campus. Faculty who think local residents are more passionate than faculty and students about athletics at their university are skeptical about the integrity of their athletics programs. Figure 4 plots faculty beliefs about their athletics departmentss adherence to regulations against their perceptions of residents' enthusiasm. As faculty perceive more external pressure on their teams to win, they become less sure their athletics programs comply with the letter of the law.

The perceived auxiliary status and faculty oversight of intercollegiate athletics are two of several indices of the structural separation available in the Faculty Survey, and conformity to rules and regulations is but one of multiple proxies for special privilege. Nonetheless, the exploratory analyses offered here clearly show how campus context - fiscal conditions and normative climate-might lead to different perceptions among faculty. Answers to the following questions would offer insights into how these different interpretations come about: To what extent is the observed acceptance of technical compliance with regulations in intercollegiate

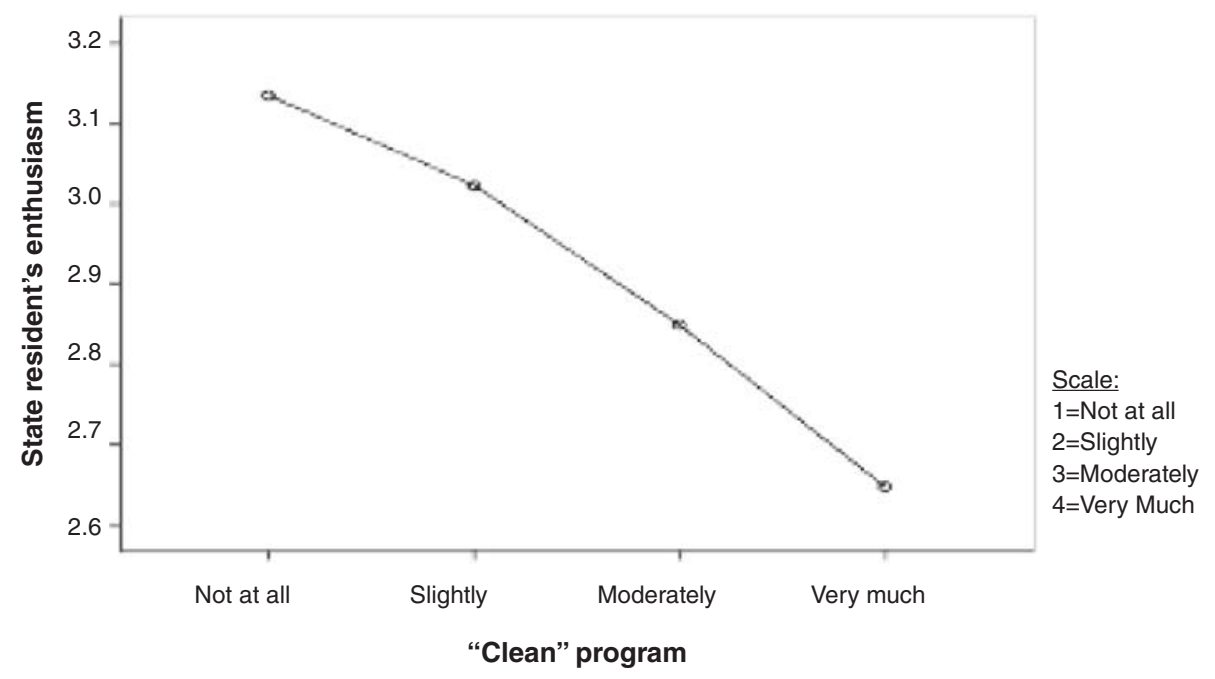

Figure 4 - Faculty perceptions of "clean" athletics programs by perceptions of state residents' enthusiasm. Response to the statements: "Residents of the state are more passionate than faculty and students about the success of our intercollegiate athletics" on the y axis, and "Over the past five years, my athletic department has run a 'clean' program (e.g., no abuses, no major violations" on the $\mathrm{x}$ axis. 
athletics a "special privilege" or symptomatic of a general shift in campus norms regarding practices that result in competitive advantages for universities? How do perceptions of off-campus conditions shape the way individuals make sense out of the complex relationship between athletics and institutional mission? How do campus norms regarding faculty participation in institutional governance affect their views of the structural separation between intercollegiate athletics, academics departments, and or student affairs?

\section{Ritualized Academic Cooperation}

Dr. Thelin's second premise is that cooperation between academics and athletics is largely ritualistic, designed to protect the special arrangements crafted by athletics departments. Coaches and faculty should both be concerned primarily with student-athletes' education. As a token acknowledgment, coaches periodically proclaim their commitment to the academic mission of their universities. Faculty reciprocate by looking the other way when special admissions procedures are applied to star athletes.

When those respondents to the Faculty Survey who teach or have taught student-athletes characterize these students in terms of academic preparation, only $21 \%$ say it is moderately to very much the case that they are not prepared to keep pace with other students in their classes. Although they are slightly less satisfied with the academic performance of football and basketball players, these faculty are about as satisfied with the performance of athletes in sports other than football and basketball as they are with nonathletes (see Figure 5). These findings suggest caution when considering overgeneralizations about the disregard for academic standards often associated with intercollegiate athletics. Faculty who teach undergraduates discern differences between the preparation and performance of football and basketball players and other student-athletes. Although this finding highlights what might be an important difference attributable to individual faculty experiences, other findings underscore the potential impact of campus context on perceptions.

Faculty and administrators on one campus where presurvey interviews were conducted noted that to achieve enrollment targets, admissions standards for the general student body were lowered. The net result was that student-athletes as a group had stronger academic records than other admitted students in their cohort. Furthermore, although space precludes a full discussion of the analyses, survey findings suggest faculty on campuses differentiated by levels of athletic and academic achievement hold different views of student quality. For example, satisfaction with the academic performance of student-athletes and the general student body coupled with a distinct concern about the pressures on student-athletes to achieve high levels of performance in their classes and in their sports characterize faculty from higher academic/higher athletic performance campuses. In contrast, dissatisfaction with the academic performance of both the general student body and student-athletes in sports other than football and basketball characterize faculty from higher academic/lower athletic performance campuses. These faculty are most satisfied with the performance of football and basketball players and show a particularly high level of concern about the quality of the educational experiences of all student-athletes. ${ }^{3}$ 
Satisfaction with Academic Performance

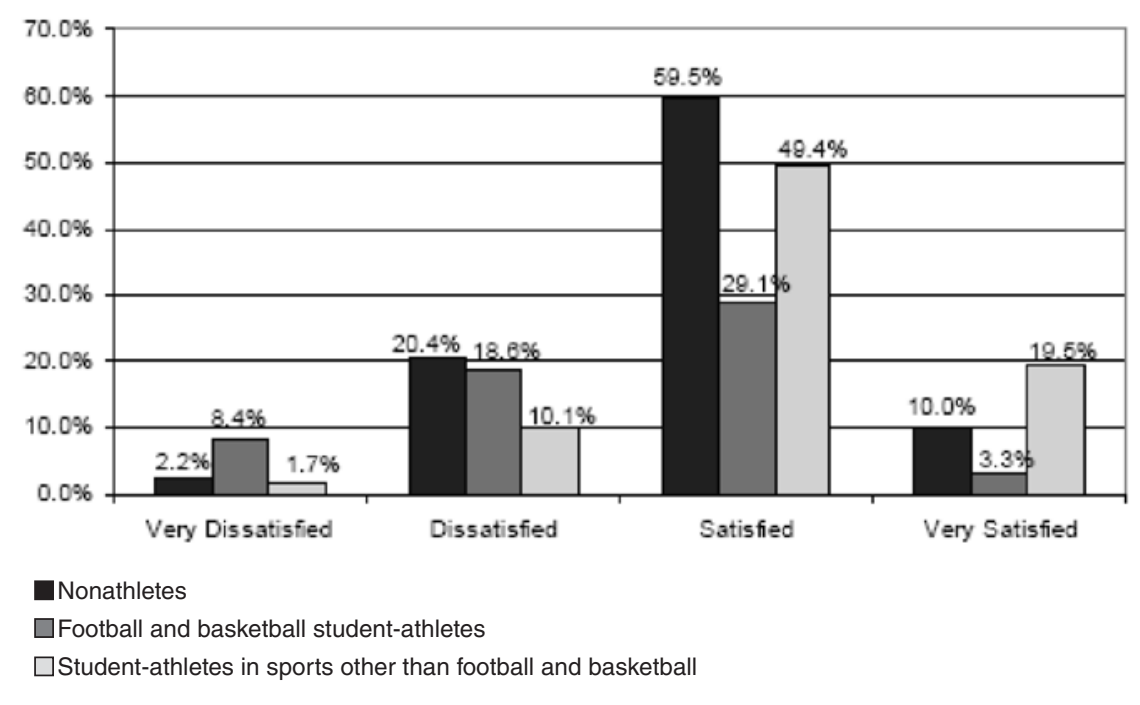

Figure 5 - Faculty satisfaction with academic performance in their classes.

Asked if their universities must compromise academic standards to remain competitive in football and basketball, half of those who answered believe it is not at all to slightly the case, whereas $32 \%$ say it is moderately to very much the case. When faculty perceptions of concessions are considered by their institution's selectivity (ACT Composite 50th percentile score for all incoming students in 2005-2006), the picture is mixed. Although those in the more selective institutions are more likely to think compromises are needed, opinions fluctuate-especially among faculty at the midrange campuses (see Figure 6). These results are inconclusive in the sense that it is unclear whether faculty believe the bar for athletics or academics should be adjusted. However, together with other findings regarding institutional context, the results suggest a variety of questions about the fit of athletics within the academy, many of which are subsumed under the general query, how do faculty integrate their beliefs about standards to be applied in academic and athletic domains and achieve a sense of what is optimal?

\section{Administrative Approval Proposition}

The third premise underlying Professor Thelin's argument is that the good arrangements athletics departments have crafted depend on tacit and direct approval from central administrators, trustees, and athletic associations. Faculty Survey items about administrators' use of authority and presidential leadership, the power of athletics departments, and the influence of the entertainment industry are relevant to this assertion. 


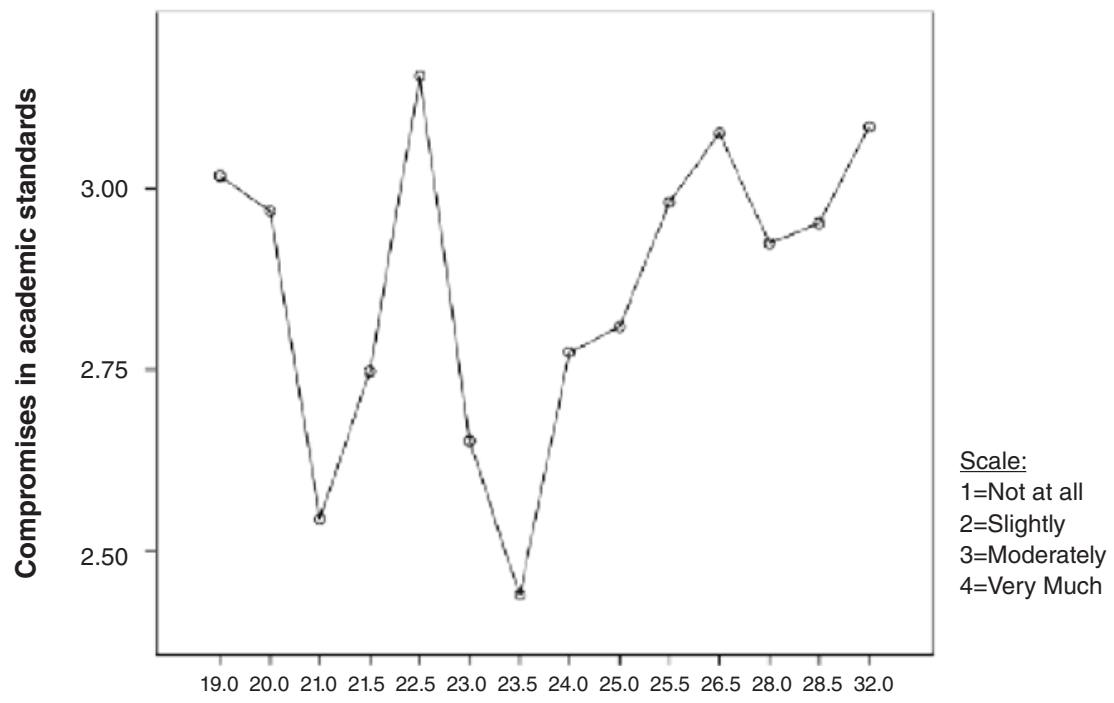

ACT composite 50th percentile score (IC2006)

Figure 6 - Faculty perceptions of compromises in academic standards by institutional selectivity (incoming student ACT score). Response to the statement: "In order for my university's football and basketball teams to be competitive, compromises in academic standards must be made."

Although a large portion (44\%) of all respondents think they lack sufficient knowledge to react, faculty split their responses to a question about administrators' use of position to foreclose discussion of intercollegiate athletics that do not fit their agendas: $29 \%$ say it is not at all to slightly characteristic of their campuses for central administrators and athletics department directors to use their power in this way, whereas $26 \%$ say it is moderately to very much characteristic. Other items related to tacit approval, such as appointing to athletics oversight committees faculty who will acquiesce to administrators, reveal similar divisions in the views of the total sample.

Another item offered respondents the opportunity to express a general concern about condoned activities, namely satisfaction with their president's oversight of intercollegiate athletics on campus. Within the total sample, the greatest portion of the faculty say they are satisfied to very satisfied (46\%) with presidential oversight. However, when NCAA violations for each of the sampled universities over the last 5 years are taken into account, significant differences appear. As the actual number of reported violations increases, faculty satisfaction declines. Satisfaction also varies in relation to faculty perceptions of the financial well being of their campus. Faculty who perceive that fiscal conditions have improved over the last 5 years are more likely to approve of institutional leadership with respect to intercollegiate athletics. On the other hand, as their satisfaction with resources for teaching and research and the priorities guiding campus budget decisions declines, so, too, does their satisfaction with the institution's management of intercollegiate athletics. 
Faculty perceptions of their athletic director's power provide an additional indication of whether faculty believe the good arrangement meets with the approval of central administrators. Again, faculty perceptions diverge. Within the total sample, faculty are split regarding their views of the relative influence of their athletic director and deans; $35 \%$ and $36 \%$, respectively, say it is not at all to slightly and moderately to very much the case that, compared with deans of schools/colleges, their athletic director has more influence with their president. The majority $(52 \%)$ of the total sample believe it is moderately to very much the case that their athletics department can use its connections with influential politicians, business leaders, and alumni to get what it wants on campus. However, when the all-time number of postseason football bowl appearances is taken to be an indication of athletics success, significant variations in faculty perspectives become evident. As shown by Figure 7, on-field success predicts faculty perceptions of athletic department power-much like a department's academic success shapes faculty views of its power on campus (Becher, 1989; Clark, 1987).

Although the Faculty Survey did not ask about trustees or athletic associations, it did include items about a group that stands to gain substantially from the good arrangements - one that Professor Thelin did not mention. Half of the total sample responding to the item says it is moderately to very much the case on their campus that decisions about intercollegiate athletics are driven by the priorities of an entertainment industry that is not invested in their university's academic mission. However, once again faculty perceptions are influenced by conditions on campus.

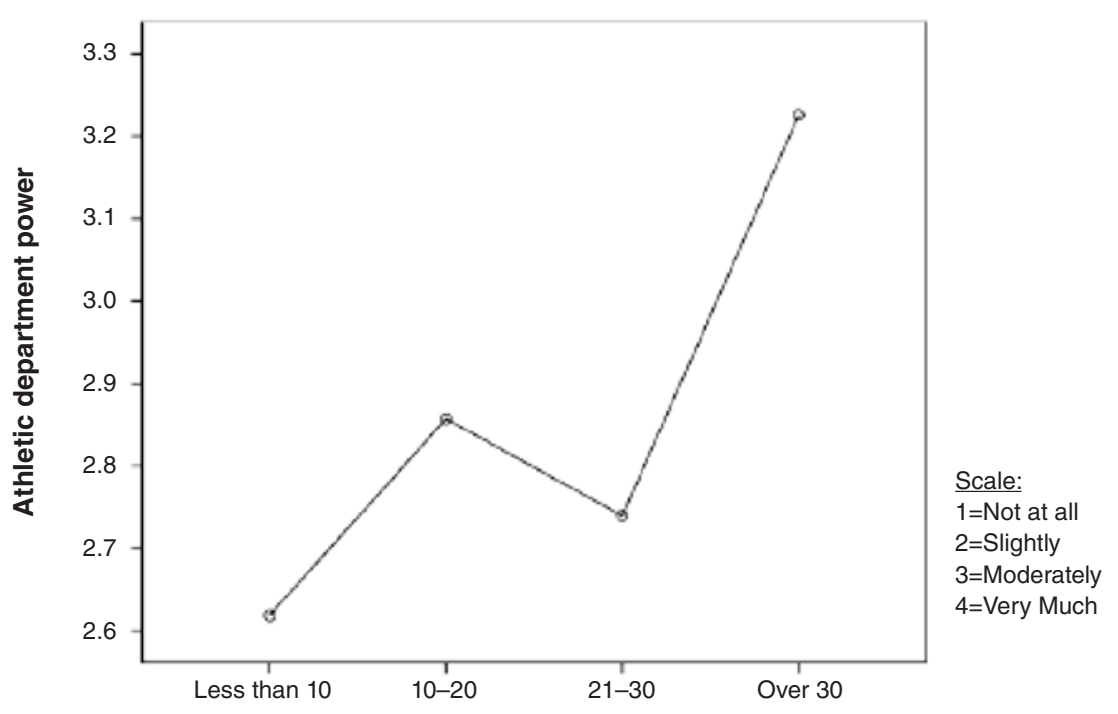

All-time football bowl appearances through 2005-06

Figure 7 - Faculty perceptions of athletic department power predicted by all-time football bowl appearances. Response to the statement: "The athletic department can use its power with influential politicians, business leaders, and alumni to get what it wants on my campus." 
Those from universities with traditions of football success (i.e., appear more often in postseason football bowls) are more likely to believe the entertainment industry exerts more influence (see Figure 8).

Do faculty share Professor Thelin's perception that athletics departments enjoy tacit and direct support of presidents and other campus administrators? The general answer is: It depends. Support is signaled by administrative actions that vary in visibility. When asked about administrators' use of power to foreclose discussions of intercollegiate athletics, many respondents say they lack relevant knowledge. Among those who could answer, perceptions fluctuated in relation to direct experience with intercollegiate athletics oversight and, as was the case in previous studies, faculty with more campus governance experience were most positive about administrators (Cockley \& Roswal, 1994). Larger portions of the sample responded to questions about the impact of administrative actions that visibly and directly affect faculty work lives, such as resource allocations to athletics and academics. In these instances, fluctuations in satisfaction with presidential oversight were predicted by faculty perceptions of institutional budget priorities, as well as financial conditions on campus.

Further evidence that campus context contributes to faculty perceptions is provided by the responses of faculty from lower academic/higher athletic performance universities. The pattern of beliefs about athletics department power and campus culture fit best with the image that Professor Thelin proffers. Faculty in

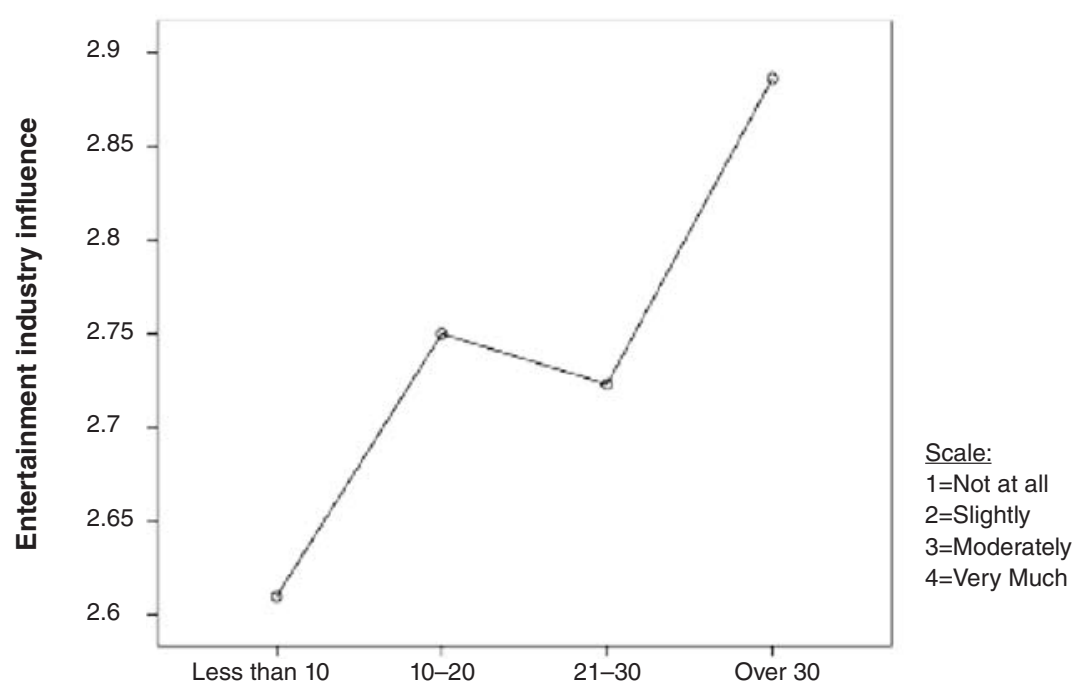

All-time football bowl appearances through 2005-06

Figure 8 - Faculty perceptions of entertainment industry influence predicted by all-time football bowl appearances. Response to the statement: "Decisions about intercollegiate athletics on my campus are driven by the priorities of an entertainment industry that is not invested in my university's academic mission." 
this institutional category perceive greater separation of athletics from academics, attribute greater power to their athletics departments and external groups, and believe athletics is favored over academics in financial decisions.

Clearly, there is a need for studies of the social networks within which athletic departments are embedded-what they look like and how they operate. Through what mechanisms do athletics departments exert influence on campus? How do campus decision makers judge academic and athletic priorities? What is the role of trustees with respect to the oversight of intercollegiate athletics? Answers to such questions will shed further light on how different individuals interpret situations and devise appropriate policies and practices.

\section{Knowledge and Caring Proposition}

Dr. Thelin argues that tactics used to protect the special arrangement-including how difficult it is to acquire information about intercollegiate athletics - eventually wear faculty down. They become disconnected and cynical. Faculty "don't know and don't care" about athletic department policies and practices.

The Faculty Survey presented respondents with a list of topics and asked them to indicate how much priority they think faculty governance on their campuses must give to each one. The results for the total sample displayed in Figure 9 show that, relative to other matters, intercollegiate athletics places next to last in terms of overall importance. Responses to other questions suggest faculty feel disconnected from decision making related to intercollegiate athletics (e.g., they tend to believe faculty are not consulted and that their input does not inform decisions in this domain).

Of the 54 Faculty Survey items about perceptions of the academic, governance, and financial aspects of intercollegiate athletics, there are 12 items to which at least $35 \%$ of the total sample responded "don't know". Some writers have interpreted this result as an indication that faculty "don't care" about athletics-if they cared they would know. In light of the findings noted in the preceding paragraph, this conclusion is tempting although not necessarily valid, logically or empirically.

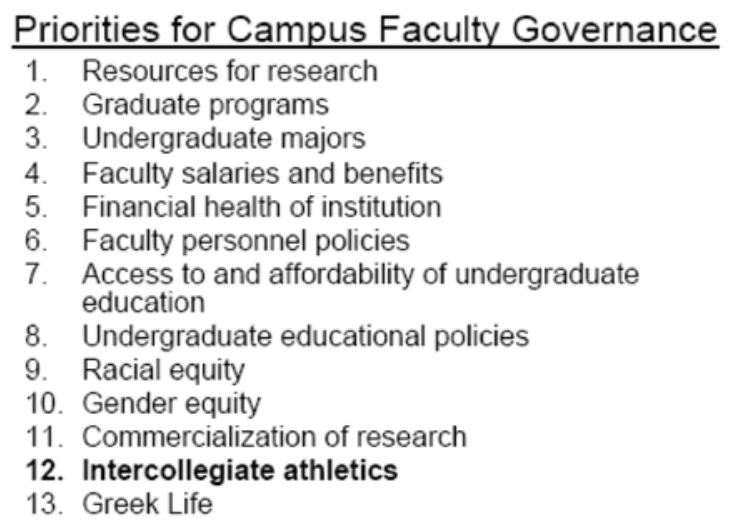

Figure 9 - Campus priorities. 
The empirical links between knowledge and caring about intercollegiate athletics were examined using logistic regression and ordinary least squares regression analyses. Three indicators of individual faculty caring were used: (a) self-reported likelihood they would join a campus initiative to address their personal concerns about intercollegiate athletics, (b) subjective estimates of the probability that faculty initiatives to address their concerns would result in meaningful change at their university, and (c) the personal priority faculty members give to intercollegiate athletics as a campus governance matter. Variables were created representing the proportion of "don't know" responses to items about the academic, governance, and financial aspects of intercollegiate athletics, and these three variables were used to predict the odds that faculty would join a campus-based initiative, as well as the odds that they believe such initiatives would lead to meaningful changes.

The results show that a lack of knowledge about finance and governance significantly decreases the odds that a faculty member would join an initiative, but lack of knowledge does not affect his or her estimate of the initiative's likely impact. These findings make sense in light of other responses from the Faculty Survey indicating that financial concerns faculty associate with athletics are diffuse and the belief that vested interests are very entrenched on their campuses. Furthermore, when the levels of knowledge data and perceived-impact data are graphed, the two lines are essentially parallel, suggesting those who are pessimistic about the impact of athletics-related campus initiatives are cynical no matter how much knowledge they profess.

When lack of knowledge is used to predict the priority ascribed to intercollegiate athletics as a governance issue, only a lack of knowledge about the academic aspects exerts a significant and negative effect on the priority that faculty give to intercollegiate athletics as a governance issue. Although this finding offers some hope that more information might lead to greater concern among faculty, preliminary evidence from the survey is indeterminate regarding the claim that because faculty lack knowledge, they don't care. More refined analyses to distinguish the factors that contribute to a lack of knowledge as well as levels of concern about intercollegiate athletics are needed. In particular, the collective findings indicate it is important to consider faculty members' sense of relative satisfaction or dissatisfaction with campus conditions, their sense of agency within their universities and if their apparent cynicism reflects personal assessments of the futility of changing intercollegiate athletics specifically or a sense of diminished influence in campus decision making generally.

\section{Concluding Thoughts}

Analyses of the Faculty Survey data conducted to date highlight conditions on and off campus that might at least partially explain why certain issues are more or less salient at different universities and why intercollegiate athletics policies and practices might be interpreted differently. The findings also underscore variations in the experiences of faculty, as well as other institutional stakeholders including academic administrators, trustees, athletics administrators, student-athletes, and the general student body that may result in distinctive interpretations of the complex relationship between athletics and academics. 
In his closing, Professor Thelin comments, "What remains most elusive to me is gaining a sense of how presidents, provosts, athletic directors, coaches, and trustees acquire interpretations and re-think policies and practices" (Thelin, 2008, p. 80) I believe this brief exploration of the views of one group within the academy_faculty_-suggests some directions for future research that will shed light on this process.

\section{Notes}

1. For a detailed discussion of survey methods and study results please see Faculty Perceptions of Intercollegiate Athletics available for downloading at http://www.knightcommission2.org/ faculty_perceptions_final.doc

2. In this response, only the results of one-way ANOVA are presented. Multivariate analyses are being completed and will be reported in the future. Unless otherwise noted, all results noted are statistically significant.

3. The 23 institutions in the sample were subdivided post hoc into four categories: Higher Academic/Higher Athletic, Higher Academic/Lower Athletic, Lower Academic/Higher Athletic, and Lower Academic/Lower Athletic performance. Higher Athletic campuses were those where the postseason success of the football and men's basketball teams over the last six years was above the median for the total sample. Higher Academic campuses were those where the NCAA 4-class average rates for football and men's basketball as well as the student selectivity index for the general student body were above the median for the total sample. See full report of study findings for details.

\section{Acknowledgements}

I wish to acknowledge and thank Ms. Molly Ott and Ms. Lori Hendricks, doctoral students in the Center for the Study of Higher and Postsecondary Education, for their contributions to the Faculty Survey and to the preparation of this response. I also wish to thank the Knight Commission on Intercollegiate Athletics for supporting the research.

\section{References}

Becher, T. (1989). Academic tribes and territories. Milton Keynes, England: Society for Research into Higher Education, Open University Press.

Clark, B.R. (1987). The academic profession: National, disciplinary and institutional settings. Los Angeles: University of California Press.

Cockley, W., \& Roswal, G. (1994). A comparison study of faculty members' perceived knowledge and satisfaction regarding NCAA athletic programs. Journal of Sport Behavior, 17(4), 217-223.

Thelin, J.R. (2008). Academics and Athletics: A Part and Apart in the American Campus. Journal of Intercollegiate Sport, 1(1), 72-81. 